\title{
Multiple policy interest rates and economic performance in a multiple monetary-policy-tool environment ${ }^{\text {is }}$
}

\author{
Serdar Varlik ${ }^{a}$, M. Hakan Berument ${ }^{\text {b,* }}$ \\ a Department of Economics, Hitit University, 19040 Corum, Turkey \\ ${ }^{\mathrm{b}}$ Department of Economics, Bilkent University, 06800 Ankara, Turkey
}

\section{A R T I C L E I N F O}

\section{JEL Codes:}

E58

E43

C32

\section{Keywords:}

Monetary policy

Multiple monetary policy tools

FAVAR

\begin{abstract}
A B S T R A C T
This paper assesses the individual effects on economic performance of different monetary policy interest rates for a central bank. To measure these effects, we employ an extension of existing Factor-Augmented Vector Autoregressive (FAVAR) models, such that the number of monetary policy variables can be captured with a few unobservable factors, as well as economic state variables with other unobservable factors. The empirical evidence from Turkey suggests that the four interest rates we consider as policy tools for the central bank affect economic state variables in different magnitudes. Thus, selecting different policy tools provides an environment that allows determining the effects of each tool for differentiated economic outcomes.
\end{abstract}

\section{Introduction}

Prior to the 2008 financial crisis, the short-term interest rate was the main tool for central banks to conduct their monetary policies with. In the post-2008 era, central banks have developed a new set of policy tools to cope with new challenges. For example, one of the main challenges for emerging markets was excess liquidity created by the central banks of developed economies, especially after late 2010. This situation led to excessive capital inflows in developing economies, excessive credit growth in the banking system, domestic currency appreciation and current account deficits, all of which threatened market stability. Within this framework, the short-term interest rate alone was not an effective policy tool for ensuring price and financial stability. Increasing interest rates did not slow economies, but stimulated them due to excess capital flows, and thus expanded credit in the banking system and increased risk in the financial system. Therefore, post-2008, central banks, especially in developing economies, have diversified their monetary policy approach by adding macroprudential tools into an unconventional monetary policy framework (Borio, 2011; Agénor and Da Silva, 2013; Sahay, Arora, Arvanitis, Faruqee, N'Diate and Griffoli, 2014). These different tools have different effects on economic variables in different channels, and affect economic state variables to different degrees due to different financial frictions. Chen, Cúrdia, and Ferrero (2012) suggest using multiple monetary policy tools for multiple monetary policy goals. For example, due to financial frictions, different interest rates may not have the same effects on variables such as consumption/saving and investment. To the extent that central banks differentiate among these effects, the adverse effect of capital flows or other policy-induced changes might be decreased (see Medina and Roldos, 2014; Ghilardi \& Peiris, 2016; Turner, 2016; Cerutti, Claessens and Leaven, 2015; Cerutti, Correa, Fiorentino, \& Segalla,

\footnotetext{
th The authors would like to thank Salih Fendoğlu, Hakan Kara, Rana Nelson, Fatih Özatay and Hande Küçük Yeșil for their valuable comments

* Corresponding author.

E-mail addresses: serdarvarlik@hitit.edu.tr (S. Varlik), berument@bilkent.edu.tr (M.H. Berument).

URL: http://berument.bilkent.edu.tr
} 
2016).

The financial environment just after the 2008 crisis forced central banks to consider not only price stability but also financial stability as their main monetary policy objectives. Since the last quarter of 2010, one such bank, the Central Bank of the Republic of Turkey (CBRT), designed an unconventional monetary policy framework employing instruments such as multiple interest rates for monetary policy setup, a reserve option mechanism (ROM) ${ }^{1}$ interest rate corridors, differentiated required reserve ratios for time deposits for commercial banks across different maturities and selling/purchasing foreign currency with options. Furthermore, the CBRT employs these different policy tools to influence different components of commercial banks' balance sheets, which affects different economic state variables differently (CBRT, 2012).

The purpose of this paper is to provide empirical evidence regarding the distinct effects of four short-term interest rates on different economic state variables. The four interest rates we consider are the Borsa Istabul (BIST) Interbank Overnight Repo and Reverse Repo Auctions Interest Rate (BIST Overnight Interest Rate hereafter), Average Funding Cost Interest Rate, Overnight Lending Interest Rate (Lending Rate hereafter) and Overnight Borrowing Interest Rate (Borrowing Rate hereafter). We chose these four interest rates because of the emphasis the CBRT placed in their reports and academic work on the distinct effects of these rates on economic performance, which we discuss in detail later in the manuscript. Here, we focus on the effects of short-term interest rates rather than on the effects of other monetary policy tools because tools such as Reserve Option Coefficient (ROC) for the ROM, or required reserve ratios for different maturities of time deposits, are constant for long periods, and thus, the evidence gathered on these variables are subject to Type II error not rejecting the null when it is false. ${ }^{2}$

To assess the effect of different short-term interest rates on economic performance then, we gather data from Turkey for the period between December 2001 and April 2016. For several reasons, Turkey provides a unique environment in which to assess the above-noted relationships: (i) Before and after the global financial crisis, the CBRT had multiple monetary policy tools and was using them simultaneously. However, the use of and the scope of this tool set has expanded since the end of 2010. (ii) Turkey is the first country to use tools such as the ROM and the Average Funding Cost Interest Rate simultaneously to conduct its monetary policy. (iii) Turkey is a market-oriented economy and economic variables do respond to policy changes (e.g. for the period we consider, Turkey did not freeze prices or fix exchange rates). (iv) Turkey is one of the few countries that have had long-term high and volatile inflation without running to higher inflation. Thus, the evidence gathered from Turkey, at least on interest rates, has a lower probability of having Type II error in its inferences. (v) In Turkey, interest rates have never reached the zero bound. Thus, an asymmetric result for policy variables on interest rate will not cause biased/inconsistent estimates. (vi) As of 2015, the Turkish economy was the eighteenth-largest in the world. This reason alone is significant, as it means we are studying a relatively important player in the global economy.

To assess monetary policy stance, conventional Vector Autoregressive (VAR) models such as Sims' (1992) and Bernanke and Blinder's (1992) use single monetary policy tools such as short-term interest rate, non-borrowed reserves or narrow money aggregates. The first contribution of our paper is to use factor analysis to account for a large number of monetary policy tools that central banks employ for conducting monetary policy. The second contribution of our paper is to employ an econometric approach that accounts for these multiple monetary policy tools that central banks may use. To be specific, we employ Bernanke, Boivin and Eliasz's (2005) FactorAugmented Vector Autoregressive (FAVAR) models for the policy tools and economic state variables; however, those authors measure a large number of the latter only with a few factors, and we use these factors both for the economic state and policy variables. Thus, we assess the effects of different short-term interest rates on economic performance, and our approach differs from previous FAVAR studies, where a single monetary policy tool is used (e.g. Bernanke, Boivin, and Eliasz (2005), Stock and Watson (2005), Blaes (2009), Boivin, Kiley, and Mishkin (2010), Baumeister, Liu, and Mumtaz (2010), Gupta, Jurgilas, and Kabundi (2010), Igan, Kabundi, Nadal de Simon and Tamirisa (2013), Soares (2013), He, Leung, and Chong (2013) and Fernald, Speigel and Swanson (2014)).

Our empirical evidence suggests that the four policy rates affect different economic state variables at different magnitudes. The BIST Overnight Interest Rate is slightly more effective for CPI inflation; the CBRT's Average Funding Cost Interest Rate is more effective for Treasury bond interest rates, consumer credit interest rates, time deposits and portfolio investments (hot money) and the Borrowing Rate is more effective for time deposits, capacity utilization ratio, current account deficits and portfolio investments than the Lending Rate is. Thus, in that capacity, we claim that a multiple-policy environment may deliver a more diverse set of outcomes compared to a single-policy setup. This fact might enable policy makers to micromanage the aspect of economic state variables they are most concerned with.

Our paper is organized as follows: In Section 2, we briefly explain the CBRT's conventional and unconventional policy interest frameworks. In Section 3, we introduce our extension of the FAVAR methodology employed by Bernanke et al. (2005). In Section 4 we present the data sets, in Section 5 we report the empirical evidence for our specification on Turkey and in Section 6 we conclude.

\section{The CBRT's interest rate policy: a brief account}

This section provides a background on the practices and developments of the monetary policy setup in Turkey between December

\footnotetext{
${ }^{1}$ The ROM allows commercial banks to meet part of their domestic currency liabilities in the CBRT with foreign currency or gold. The CBRT does not pay interest on these liabilities; the interest rate on Turkish Lira (TL)-denominated deposits is above the foreign exchange (FX)-denominated deposits in the markets. Thus, with the ROM, the CBRT allows commercial banks to decrease the cost of meeting these obligations. As the CBRT requires higher amounts of FX or gold depending on the level of TL-denominated obligations by increasing the Reserve Option Coefficients (ROC), it tightens the country's monetary policy stance. See Sahin et al. (2015) for the details and workings of the ROM in Turkey.

${ }^{2}$ We also gathered the estimates for these policy variables (not reported here but available on request), and indeed, the gathered impulse responses had wide confidence bands.
} 
2001 and April 2016, the period that we consider in this paper for the empirical analyses.

Prior to the 2008 financial crisis, the CBRT had been primarily using short-term interest rate as a tool to attain its inflation target. Due to excess liquidity conditions in the market, the CBRT had announced that from early 2002 to May 2008 the Borrowing Rate would be the benchmark interest rate for its monetary policy (CBRT, 2015), using the short-term interest rate to provide price stability in a conventional inflation targeting regime. Within this framework the CBRT used additional tools, (i.e. required reserve ratios, interest rate in a discount window, late liquidity windows on overnight borrowing and overnight lending interest rates, various Turkish Lira (TL) liquidity tools, foreign exchange purchasing/selling auctions and options as well as foreign exchange purchasing/selling interventions), however, the Borrowing Rate was the main policy tool.

Just after the 2008 crisis, quantitative easing policies in developed economies increased global liquidity and intensified short-term capital inflows to emerging markets, including Turkey. Correspondingly, credit growth increased, currency appreciated and the current account deficit widened (Özatay, ${ }^{3}$ 2011; Kara, ${ }^{4}$ 2012; Ganioğlu, 2012; Ekinci, Erdem, \& Kilinc, 2015). Given this financial environment, the CBRT gradually transformed its monetary policy framework by adding a secondary objective - financial stability - to its main monetary policy objective - price stability - after October 2010 (CBRT, 2012). This new monetary policy design was called mixed inflation targeting $++\left(\right.$ IT ++ ) by CBRT Governor Başçõ (2013), ${ }^{5}$ and Oduncu, Ermisoglu, and Polat (2013a). To explain, the first + in IT ++ corresponds to credit growth and the second + is for real exchange rate. These variables are accepted as key indicators of financial stability by the CBRT (Başçõ \& Kara, 2011; Kara, 2012; Özatay, 2011). To achieve price stability and financial stability simultaneously and thus enhance monetary policy efficiency, the CBRT expanded its monetary policy tools by adding the following short-term interest rates to the overnight interbank interest rate: Discount Rate, Late Liquidity Window Overnight Borrowing Interest Rate, Late Liquidity Window Lending Interest Rate, One-Week Maturity Repo Auctions Interest Rate and Average Funding Cost Interest Rate. In the foreign exchange market, the CBRT uses the ROM on foreign currency and gold, foreign exchange purchasing/selling auctions and foreign exchange purchasing/selling interventions. The CBRT has also been using various liquidity measures (such as differentiated reserve requirements) on TL and foreign deposits. Thus, its new unconventional monetary policy framework consists both of structural tools (such as the reserve requirement ratio (RRR) and the ROM) as well as cyclical tools (such as the variety of short-term interest rates noted above, liquidity management tools and an interest rate corridor system) (CBRT, 2010a; 2012).

The remainder of this section elaborates on the workings of the CBRT's short-term interest rate policy. Since May 2008, as the liquidity shortage has emerged, the CBRT has supplied liquidity into the market with one-week maturity repo auctions. Since October 2008, when the global financial turmoil began to accelerate, the CBRT has ensured the liquidity of an amount significantly above the market's net liquidity need by injecting one-week maturity repo auctions into the system but at the end of the day, the CBRT withdraws this excess liquidity from the market via overnight transactions. Further, when after October 2008 the liquidity shortage dramatically increased because of capital outflows from Turkey, the CBRT began to support one-week maturity repo auctions by implementing threemonth repo auctions. In April 2010, the CBRT decided to gradually decrease the amount of excess liquidity in the market by announcing a Monetary Policy Exit Strategy (CBRT, 2010b). As a result of this policy transformation, the One-Week Maturity Repo Auctions Interest Rate started to increase. In response, the CBRT implemented a technical interest rate adjustment in May 2010, and since then, the OneWeek Repo Interest Rate has been the new monetary policy interest rate, ${ }^{6}$ with the aim of not only price stability but also financial stability. Furthermore, in order to achieve both goals simultaneously, the One-Week Maturity Repo Auctions Interest Rate has been supported through the liquidity management tool and an asymmetric interest rate corridor system, especially since October 2010. As explained below, the latter is an active monetary policy tool, different than the interest rate corridor in the CBRT's conventional monetary policy period (CBRT, 2009; 2010a; 2012).

The asymmetric interest rate corridor system consists of different short-term interest rate tools, including Lending Rate, Borrowing Rate, BIST Overnight Interest Rate, One-Week Maturity Repo Auctions Interest Rate and Average Funding Cost Interest Rate. While the Borrowing Rate is the lower band of the corridor system, the Lending Rate (also called the marginal funding rate) is the upper band of the corridor system. The CBRT sets the One-Week Maturity Repo Auctions Interest Rate, which is between the lower and upper bands, as its official policy interest rate. The CBRT also adjusts the width of the interest rate corridor around the official policy interest rate asymmetrically. Because of these two factors, the CBRT differentiates liquidity facilities to financial markets in various forms and via various channels, such as Open Market Operations (OMO), with different maturities, discount windows and additions to short-term interest rates through a set of strict limits on their usage and costs. For example, the CBRT approximates the Average Funding Cost Interest Rate to the level of the upper bound of the corridor system by reducing provided liquidity facilities via the One-Week Maturity Repo Auctions Interest Rate, where that rate is determined to be lower than the Lending Rate in the banking system. Therefore, banks are forced to borrow to meet their liquidity requirements from the Lending Rate when the CBRT tightens monetary policy or increases commercial banks' borrowing costs. Thus, the Average Funding Cost Interest Rate is higher than the lower bound of the corridor and the official policy interest rate (CBRT, 2015).

The multiple interest-rate-policy system allows the CBRT to micromanage the economic outcomes of its monetary policy, which is necessary because these short-term interest rates affect economic state variables differently and in different degrees (CBRT, 2012). For example, as suggested by the CBRT's chief economist (Kara, 2015), the Lending Rate is considered the benchmark for commercial banks'

\footnotetext{
3 A former CBRT deputy governor and a former member of the CBRT's Monetary Policy Commission.

4 Chief economist of the CBRT.

5 His tenure as CBRT governor ended April 19, 2016.

${ }^{6}$ We did not examine the effects of the One-Week Maturity Repo Auctions Interest Rate on economic performance because this factor is important in the Average Funding Cost Interest Rate. Further, banks can borrow from the One-Week Maturity Repo Auctions Interest Rate at their own limits and that rate was not an active monetary policy tool in Turkey before the global crisis.
} 
credit interest rates, the Borrowing Rate affects short-term capital flows and the Average Funding Cost Interest Rate reflects the average cost of central bank funding for commercial banks and affects their deposit rates.

The multiple interest rate policy system is conducted in a countercyclical manner, where the CBRT experiences two different monetary policy applications. The first of these applications focuses on preventing excessive credit growth, and for this purpose, the CBRT increases the Lending Rate without changing the One-Week Maturity Repo Auctions Interest Rate. This application (expanding the interest rate corridor system in an upward direction) is supported by liquidity management, where the CBRT urges banks to borrow from a more expensive funding facility at overnight rates when needed: The CBRT itself provides only a fraction of banks' total liquidity requirements by using cheaper One-Week Maturity Repo Auctions Interest Rate in limited quantities, which are announced on a monthly basis. The rest of banks' total liquidity requirements are provided via an overnight marginal funding interest rate on a daily basis, which is more expensive. As a result of this tighter monetary policy stance, the increasing volatility of the Average Funding Cost Interest Rate discourages banks from excessive credit growth (Binici, Erol, Kara, Özlü, \& Ünalmõş, 2013; Dogan Sahin and Berument, 2016; Kara, 2015; Mumtaz and Zanetti, 2013).

The second of these monetary policy applications involves smoothing the volatility of short-term capital flows and therefore also decreasing exchange rate volatility. For this purpose, the CBRT decreases the predictability of monetary policy by decreasing the Borrowing Rate during capital inflows and in a high risk-appetite period. This application is also expected to reduce commercial banks' funding costs from the CBRT and reduce investors' short-term yields. Adversely, the CBRT increases the Borrowing Rate to increase monetary policy predictability during capital outflows and in a low risk-appetite period. However, the CBRT increases the marginal funding interest rate when global liquidity narrows (Aysan, Fendoglu and Kilinc, 2014; Küçük, Özlü, Tanaslõ, Ünalmõş and Yüiksel, 2014) $)^{7}$.

\section{Methodology}

Small-scale VAR models use a limited information data set that usually includes between five and nine variables to model any macroeconomic dynamic structure and analyze the effects of a policy shock on economic performance. When central banks set up their monetary policies, however, they consider a large number of real and financial variables to predict the effects of changes their policy reactions (see for example, Kozicki, 2001). Thus, small-scale VAR models suffer from the omitted-information problem (Soares, 2013; Vargas-Silva, 2008), thus are not, as Bernanke et al. (2005) maintain, appropriate methodologies with which to analyze monetary policy shocks because they may result in biased estimates. Bernanke et al. (2005) suggest using FAVAR models to address these problems: the FAVAR reduces a set of variables that is likely to be followed by central banks to only a few variables without a big loss of information by extracting a limited number of factors from a large data set.

Bernanke et al.'s (2005) FAVAR model looks at the effects of a monetary policy shock on economic performance. They use only one policy tool - the Federal Funds Rate - and the purpose of their paper is to assess the effects on economic performance of an unanticipated change in a single central bank policy tool. In the current paper, our specification allows that a central bank employs multiple policy tools such that (i) each policy tool may have a different effect on economic state variables and (ii) as one interest rate changes, the central bank's other policy tools may adjust to decrease the adverse effects of the interest rate change or to increase the effectiveness of this policy tool. To allow for this scenario, we extend the existing FAVAR model to include various monetary policy variables and to capture the dynamic relationships among monetary policy and economic state variables by using their unobservable common factors.

To incorporate the above features, let $X_{t}$ be an $N \mathrm{x} 1$ vector for the economic state variables; $Z_{t}$ be a $\mathrm{n} M \mathrm{x} 1$ vector for the policy variables and $R_{t}$ be an observable policy variable. $F_{t}$ is an $n \times 1$ vector of the unobservable common factors for economic state variables, which captures most of the variability in $X_{t}$, and $G_{t}$ is an $m \times 1$ vector of the unobservable common factors for the policy variables, which captures most of the variability in $Z_{t}$. Following Bernanke et al. (2005), the joint dynamics of $\left[F_{t}, G_{t}, R_{t}\right]$ ' might be captured by

$$
\left[\begin{array}{c}
F_{t} \\
G_{t} \\
R_{t}
\end{array}\right]=\Phi^{*}(L)\left[\begin{array}{c}
F_{t-1} \\
G_{t-1} \\
R_{t-1}
\end{array}\right]+v_{t} \Leftrightarrow \Phi(L)\left[\begin{array}{c}
F_{t} \\
G_{t} \\
R_{t}
\end{array}\right]=v_{t}
$$

where $\Phi(L)=I-\Phi^{*}(L) L=I-\Phi_{1} L-\ldots-\Phi_{d} L^{d}$, in which $L$ is the lag operator, $I$ is the conformable identity matrix, $d$ is the order of polynomial $\Phi(),. \Phi_{i}(i=1, \ldots, d)$ is the conformable coefficient matrix and $v_{t}$ is the error term. Note that Equation (1) is an analogue of the VAR model that Bernanke et al. (2005) label FAVAR, which includes both observable and unobservable variables. In other words, the selected observed policy variable $R_{t}$ interacts with two separate sets of factors: economic state variables and policy variables, where Bernanke et al.'s (2005) FAVAR had the economic state variables $F_{t}$ but not $G_{t}$. Moreover, FAVAR models, like regular VAR models, may also contain a set of prior restrictions.

Note that since factors $F_{t}$ and $G_{t}$ are not directly observable, Equation (1) cannot be estimated directly. Here, we can interpret that factors $F_{t}$ and $G_{t}$ are the common forces driving both the state of the economy and the rest of the monetary policy stance that is not captured by the observable single policy tool $R_{t}$. Thus, these three sets of variables $\left(F_{t}, G_{t}\right.$ and $\left.R_{t}\right)$ capture the dynamics of the economy. Similar to Bernanke et al. (2005), we assume that the following specification captures the relationships among the three sets of variables:

\footnotetext{
${ }^{7}$ A former member of the CBRT's Monetary Policy Commission.
} 


$$
\left[\begin{array}{c}
X_{t} \\
Z_{t} \\
R_{t}
\end{array}\right]=\left[\begin{array}{ccc}
\Lambda^{X f} & \Lambda^{X g} & \Lambda^{X r} \\
\Lambda^{Z f} & \Lambda^{Z g} & \Lambda^{Z r} \\
0 & 0 & \mathrm{I}
\end{array}\right]\left[\begin{array}{c}
F_{t} \\
G_{t} \\
R_{t}
\end{array}\right]+\left[\begin{array}{c}
e_{t}^{X} \\
e_{t}^{Z} \\
0
\end{array}\right]
$$

Here, $\Lambda$ s are conformable matrices for the factor loadings, and $e_{t}^{X}$ and $e_{t}^{Z}$ are the zero mean, weakly cross-sectionally correlated but not an autocorrelated error term. Following Bernanke et al. (2005) and Stock and Watson (1998), $X_{t}$ and $Z_{t}$ depend on the current values of $F_{t}, G_{t}$ and $R_{t}$ rather than on their lag values. Once we assume $m+n<<M+N$, then the amount of information handled in the FAVAR will be considerably smaller than the corresponding VAR that includes all the relevant variables.

We follow a two-step approach similar to Bernanke et al. (2005) to estimate the FAVAR model as specified in Equations (1) and (2). In the first step, we gathered $F_{t}$ factor variables from $X_{t}$ that consist of only economic state variables and $G_{t}$ factor variables from $Z_{t}$ that consist of only monetary policy variables by using principal component analysis, where the number of factors for each matrix $X_{t}$ and $G_{t}$ is determined by Bai and Ng's (2002) IC 2 test statistics, where the gathered factors are labelled as $\widehat{F}_{t}$ and $\widehat{G_{t}}$. In the second step, we gathered the estimates for the parameters of the VAR model as specified in Equation (1) by replacing $F_{t}$ and $G_{t}$ with $\widehat{F}_{t}$ and $\widehat{G}_{t}$. To determine the factors in Equation (1), however, unlike Bernanke et al. (2005), we do not place the policy tools into the state variables. ${ }^{8}$

The structural equation that captures the dynamics can be written as

$$
\psi(L)\left[\begin{array}{c}
\widehat{F}_{t} \\
\widehat{G}_{t} \\
R_{t}
\end{array}\right]=\varepsilon_{t}
$$

where $\widehat{\psi}(L)=\widehat{\psi}_{0}-\widehat{\psi}_{1} L-\widehat{\psi}_{2} L^{2}-\ldots-\widehat{\psi}_{d} L^{d}$ is a $d^{\text {th }}$ order polynomial matrix, $L$ is the lag operator and $\varepsilon_{t}$ is the vector for structural innovations.

In order to identify the policy shocks in Equation (3), we employ the Cholesky decomposition with a lower triangular identifying matrix. For the identification, we allow policy variables $R_{t}$ and $G_{t}$ to affect the unobservable economic state variables $F_{t}$ contemporaneously, not vice versa. This approach is parallel with the assumption that monetary policy variables move faster than economic state variables. Moreover, allowing monetary policy variables to affect the economic state variables contemporaneously is a wellestablished identification scheme through the Cholesky decomposition for Turkey (see Berument, 2007; Ceylan, Dogan, \& Berument, 2014). However, all the variables affect each other with a lag. Here, ordering each factor for each economic state and monetary policy variable does not matter because each group of factors within each group is orthogonal to one other. Moreover, we place the observable policy variable after the policy factors, which is parallel with Strongin (1995). This allows that once the observable policy variable changes, the other policy variables adjust accordingly. Once these factors' effects are controlled for, we observe how the economic state variables respond. As a robustness analyses, we perform a set of alternatives; one of them includes both monetary policy variables and economic state variables in one set of vectors, that is, there are no $Z_{t}$ or $G_{t}$ matrices but $X_{t}$ includes both sets of variables. Second, we include policy factor $\left(G_{t}\right)$ vectors only as control variables and do not allow feedback from $R_{t}$ and $F_{t}$ to $G_{t}$. Third. we exclude $Z_{t}$ and $G_{t}$ vectors completely from the analyses. These specifications and the gathered inferences will be discussed later in detail.

For the FAVAR specification, we determine the lag order of the model as three by using the sequential modified Likelihood Ratio Test Statistic and the Bayesian Information Criteria. We also place 11 seasonal dummy variables to account for seasonality, a crisis dummy for September 2008, an unconventional monetary policy dummy for the post-November 2010 era and a ROM dummy for the postSeptember-2011 era, when the CBRT began to use the ROM as a policy tool to affect economic performance (see Sahin, Dogan, \& Berument, 2015). Turkey is a small open economy, thus developments in international financial markets and world economy affect the country's economic performance. Thus, we include three factor variables that capture most of the external developments for Turkey, which will be discussed in the data section.

In order to get the impulse responses, we employ the following equation

$$
\left[\begin{array}{c}
\widehat{F}_{t} \\
\widehat{G}_{t} \\
Y_{t}
\end{array}\right]=\widehat{\delta}(L) \varepsilon_{t}
$$

where $\widehat{\delta}(L)=[\widehat{\psi}(L)]^{-1}=\widehat{\delta}_{0}+\widehat{\delta}_{1} L+\ldots+\widehat{\delta}_{h} L^{d}$ is a $d^{\text {th }}$ degree polynomial, $L$ is the lag operator and $\delta_{j}$ are conformable coefficient matrices. The estimation for $X_{t}$ can be gathered from Equation (2) as $\widehat{X}_{t}=\widehat{\Lambda}^{X f} F_{t}+\widehat{\Lambda}^{X g} G_{t}+\widehat{\Lambda}^{X r} R_{t}$. Then, the impulse response for each variable in $X_{t}$ can be gathered as

$$
\left[\begin{array}{c}
X_{t}^{I R F} \\
Z_{t}^{I R F} \\
R_{t}^{I R F}
\end{array}\right]=\left[\begin{array}{ccc}
\widehat{\Lambda}^{X f} & \widehat{\Lambda}^{X g} & \widehat{\Lambda}^{X r} \\
\widehat{\Lambda}^{Z f} & \widehat{\Lambda}^{Z g} & \widehat{\Lambda}^{Z r} \\
0 & 0 & \mathrm{I}
\end{array}\right]\left[\begin{array}{l}
\widehat{F}_{t} \\
\widehat{G}_{t} \\
R_{t}
\end{array}\right]=\left[\begin{array}{ccc}
\widehat{\Lambda}^{X f} & \widehat{\Lambda}^{X g} & \widehat{\Lambda}^{X r} \\
\widehat{\Lambda}^{Z f} & \widehat{\Lambda}^{Z g} & \widehat{\Lambda}^{Z r} \\
0 & 0 & \mathrm{I}
\end{array}\right] \widehat{\delta}(L) \varepsilon_{t}
$$

\footnotetext{
${ }^{8}$ Note that Bernanke et al. (2005) have one policy tool. They order the economic state variables in $X_{t}$ from fastest to slowest. They also place the policy variable into this $X_{t}$ vector. As discussed by Soares (2013), this method did not alter the results. We have multiple policy tools, and placing these tools' factors into $X_{t}$ and identifying the system is not possible. Thus, we assume that the monetary policy variables are placed after the economic state variables can be affected by a single observable monetary policy tool and the rest of the monetary policy tools.
} 
Table 1

CBRT monetary policy tools.

\begin{tabular}{|c|c|c|c|c|}
\hline \# & Series Name & Treatment & Acronym & Sources \\
\hline 1 & Reserve Requirement Ratio of TL Deposits & 1 & RRRTL & CBRT \\
\hline 2 & Reserve Requirement Ratio of Foreign Currency Deposits & 1 & RRRFX & CBRT \\
\hline 3 & Discount Rate & 1 & DSCNT & CBRT \\
\hline 4 & Late Liquidity Window Borrowing Rate & 1 & LONBRW & CBRT \\
\hline 5 & Late Liquidity Window Lending Rate & 1 & LONLR & CBRT \\
\hline 6 & Foreign Exchange Purchasing Intervention over International Reserve & 1 & FXPI & CBRT \\
\hline 7 & Foreign Exchange Selling Intervention over International Reserve & 1 & FXSI & CBRT \\
\hline 8 & ROM Gold Utilization Rate & 1 & ROMGLDUR & CBRT \\
\hline 9 & ROM Foreign Currency Utilization Rate & 1 & ROMFCUR & CBRT \\
\hline 10 & ROM Gold over International Reserve & 1 & ROMGLD & CBRT \\
\hline 11 & ROM Foreign Currency over International Reserve & 1 & ROMFC & CBRT \\
\hline 12 & Foreign Exchange Purchasing Auctions over International Reserve & 1 & FXPA & CBRT \\
\hline 13 & Foreign Exchange Selling Auctions over International Reserve & 1 & FXSA & CBRT \\
\hline 14 & Central Bank Money & 3 & CBM & CBRT \\
\hline 15 & Monetary Base & 3 & MB & CBRT \\
\hline 16 & Reserve Money & 3 & $\mathrm{RM}$ & CBRT \\
\hline 17 & Open Market Operation over CBRT's Total Assets & 1 & OMO & CBRT \\
\hline 18 & One-Week Repo Auctions Interest Rate & 1 & OWINT & CBRT \\
\hline 19 & Overnight Borrowing Interest Rate & 1 & BRWINT & CBRT \\
\hline 20 & Overnight Lending Interest Rate & 1 & LRINT & CBRT \\
\hline 21 & BIST Overnight Repo and Reverse Repo Interest Rate & 1 & BISTON & CBRT \\
\hline 22 & Interbank Overnight Minimum Interest Rate & 1 & INTONMIN & Thomson Reuters DataStream \\
\hline 23 & Interbank Overnight Average Interest Rate & 1 & INTONAVG & Thomson Reuters DataStream \\
\hline 24 & Interbank Overnight Maximum Interest Rate & 1 & INTONMAX & Thomson Reuters DataStream \\
\hline 25 & Average Funding Cost Interest Rate & 1 & WACF & CBRT \\
\hline
\end{tabular}

Note: Treatment shows how the series is transformed before added to the database, with $1=\operatorname{level}$ and $3=\log$ difference.

In order to gather another set of inferences from the VAR estimates, we employ the Forecast Error Variance Decomposition (FEVD) exercise, which is the portion of the variance of forecasting error of a variable that can be attributed to a given shock at given time $t$. If $\widehat{X}_{t+h / t}$ is the $h$ period ahead of forecast $X_{t}$ on time $t$ with given information at time $t$, then the forecast error is $X_{t+h}-\widehat{X}_{t+h / t}$. Thus, the fraction of the variance of the forecast error that is due to interest rate shock, $\varepsilon_{t}^{R}$, can be represented as

$$
\frac{\operatorname{Var}\left(X_{t+h}-\widehat{X}_{t+h / t} / \varepsilon_{t}^{R}\right)}{\operatorname{Var}\left(X_{t+h}-\widehat{X}_{t+h / t}\right)}
$$

\section{Data}

Our data span, which comprises monetary policy tools, economic state variables and external variables, covers a monthly observation from December 2001 to April 2016. Table 1 presents the CBRT's 25 conventional and unconventional monetary policy tools, as well as their transformation treatments, acronyms and sources. Table 2 provides the data set of the 59 economic state variables that reflect Turkish economic performance, and their transformation treatments, acronyms and sources. These variables were selected due to the availability and reliability of the series. Furthermore, we consider that Turkey is a small open economy, and therefore, domestic variables may be affected by external variables. Table 3 reports the list of these six external variables, and their transformation treatments, acronyms and sources used in the analyses. These external factors are used as the control variables.

We performed a set of unit root tests to determine whether these series have a long-run constant mean. The test statistics suggest that the series are stationary and thus we treat them all as stationary. We also perform the Im, Pesaran, Shin (2003) panel unit root test to determine the robustness of these tests, and we reject the null of the unit root again (these tests are not reported here to save space but are available from the authors upon request).

Following Bernanke et al. (2005) and Stock and Watson (2005), we impose the identifying assumption for ordering by ranking the variables from slow moving to fast moving in each type of data set. The Bai-Ng Factor Determination Test is used to determine the number of factors for the economic state variable vector $X_{t}$ and the monetary policy variable vector $Z_{t}$. The test results are reported in Table 4 and Table 5, respectively. The test results for the former suggest that for the three test statistics, the number of factors is three for the monetary policy tools. ${ }^{9}$ These three factors explain $69 \%$ of the total variation in the 25 monetary policy tools. The test results for the latter suggest that for the five test statistics, the number of factors is five for the economic state variables. These five factors explain $99 \%$ of the total variation in the 59 economic state variables. We also implement the Bai-Ng Factor Determination Test for the external variables. The test results reported in Table 6 show that for the three test statistics, the number of factors is three for the external variables. These three factors explain $82 \%$ of the total variation in the six external variables.

\footnotetext{
${ }^{9}$ By construction, these factors are orthogonal to each other, thus, excluding a relevant fourth or higher factor will not make the inferences inconsistent.
} 
Table 2

Economic state variables.

\begin{tabular}{|c|c|c|c|c|}
\hline \# & Series Name & Treatment & Acronym & Sources \\
\hline 1 & Number of Dwellings (Residential Buildings) & 3 & BUILT & CBRT \\
\hline 2 & Number of New Firms & 3 & FIRM & CBRT \\
\hline 3 & Number of Registered Road Motor Vehicles & 3 & RMV & CBRT \\
\hline 4 & Unemployment Rate & 1 & UNEMP & CBRT \\
\hline 5 & Government Consumption (Constant Prices) & 3 & GCNS & CBRT \\
\hline 6 & Private Consumption (Constant Prices) & 3 & PCNS & CBRT \\
\hline 7 & Industrial Production & 3 & IP & CBRT \\
\hline 8 & Industrial Production of Manufacturing & 3 & IPM & CBRT \\
\hline 9 & Capacity Utilization Rate & 1 & СРCTY & CBRT \\
\hline 10 & Real Sector Confidence Index & 3 & RCONF & CBRT \\
\hline 11 & Gross Fixed Capital Formation (Constant Prices) & 3 & GFCF & CBRT \\
\hline 12 & Stocks over GDP (Constant Prices) & 1 & STCKS & CBRT \\
\hline 13 & Net Export over GDP (Constant Prices) & 1 & $\mathrm{NX}$ & CBRT \\
\hline 14 & Implicit Price Deflator & 3 & IPD & CBRT \\
\hline 15 & $\mathrm{CPI}(\mathrm{H})$ & 3 & HCPI & CBRT \\
\hline 16 & CPI (I) & 3 & ICPI & CBRT \\
\hline 17 & CPI & 3 & CPI & CBRT \\
\hline 18 & PPI & 3 & PPI & CBRT \\
\hline 19 & Budget Expenditures over Budget Revenues & 1 & BDGTEXP & CBRT \\
\hline 20 & Budget Interest Rate Payments over Budget Revenues & 1 & BDGTINT & CBRT \\
\hline 21 & Government External Debt over GDP & 1 & GEXDBT & CBRT \\
\hline 22 & Financial Sector External Debt over GDP & 1 & FEXDBT & CBRT \\
\hline 23 & Non-financial Sector External Debt over GDP & 1 & NFEXDBT & CBRT \\
\hline 24 & Long-term External Debt over GDP & 1 & LREXDBT & CBRT \\
\hline 25 & Short-term External Debt over GDP & 1 & SREXDBT & CBRT \\
\hline 26 & Direct Investment over GDP & 1 & DRINV & CBRT \\
\hline 27 & Current Account Balance over GDP & 1 & $\mathrm{CAB}$ & CBRT \\
\hline 28 & Trade Term & 3 & TRDTERM & Thomson Reuters Data Stream \\
\hline 29 & Broad Definition of Hot Money over GDP (authors' calculation) & 1 & HOT & CBRT \\
\hline 30 & Net Error and Omission over GDP & 1 & NEO & CBRT \\
\hline 31 & Gross International Reserve & 3 & IRRES & CBRT \\
\hline 32 & Net International Reserve & 3 & NIRRES & CBRT \\
\hline 33 & M3 & 3 & M3 & CBRT \\
\hline 34 & M2 & 3 & M2 & CBRT \\
\hline 35 & M1 & 3 & M1 & CBRT \\
\hline 36 & FX Deposits & 3 & FXD & CBRT \\
\hline 37 & Demand Deposits & 3 & $\mathrm{DD}$ & CBRT \\
\hline 38 & Time Deposits & 3 & $\mathrm{TD}$ & CBRT \\
\hline 39 & Growth of Credits to Private Sector & 1 & CRDT & CBRT \\
\hline 40 & Growth of Consumer Credits & 1 & CNSCRDT & CBRT \\
\hline 41 & Commercial EU Credit Interest Rate & 1 & CMEUCRDT & CBRT \\
\hline 42 & Commercial USD Credit Interest Rate & 1 & CMUSCRDT & CBRT \\
\hline 43 & Commercial TL Credit Interest Rate & 1 & CMTLCRDT & CBRT \\
\hline 44 & Consumer Credit Interest Rate & 1 & CRDTCNS & CBRT \\
\hline 45 & Residential TL Credit Interest Rate & 1 & CRDTRSTL & CBRT \\
\hline 46 & Vehicle TL Credit Interest Rate & 1 & CRDTVTL & CBRT \\
\hline 47 & Need TL Credit Interest Rate & 1 & CRDTNDTL & CBRT \\
\hline 48 & More-than-One-Year Deposit Interest Rate & 1 & DEPLR & \\
\hline 49 & Six-Month Deposit Interest Rate & 1 & DEPSIX & CBRT \\
\hline 50 & Three-Month Deposit Interest Rate & 1 & DEPTHREE & CBRT \\
\hline 51 & One-Month Deposit Interest Rate & 1 & DEPONE & CBRT \\
\hline 52 & Treasury Bond Interest Rate & 1 & DIBSINT & Undersecretariat of Treasury of Republic of Turkey Prime Ministry \\
\hline 53 & $\mathrm{EMBI}+\mathrm{TR}$ & 3 & EMBITR & Thomson Reuters Data Stream \\
\hline 54 & MSCI TR & 3 & MSCITR & Thomson Reuters Data Stream \\
\hline 55 & BIST-100 & 3 & BIST & CBRT \\
\hline 56 & Real Effective Exchange Rate & 3 & REER & CBRT \\
\hline 57 & USD Exchange Rate & 3 & USD & CBRT \\
\hline 58 & EURO Exchange Rate & 3 & EURO & CBRT \\
\hline 59 & Exchange Rate Basket & 3 & EXCHBSKT & CBRT \\
\hline
\end{tabular}

Note: Treatment shows how the series is transformed before added to the database, with $1=\operatorname{level}$ and $3=\log$ difference.

\section{Empirical evidence}

Fig. 1 reports the impulse response functions of the 16 economic state variables that we consider when a one-standard-deviation shock is given to each policy interest rate that we consider: BIST Overnight Interest Rate, Average Funding Cost Interest Rate, Lending Rate (upper band of the interest-rate corridor) and Borrowing Rate (lower band of the interest-rate corridor). The middle line in the figure is for the impulse responses for the 18 periods and the dotted lines are one-standard-deviation confidence bands. If the confidence 
Table 3

External variables.

\begin{tabular}{llll}
\hline$\#$ & Series Name & Treatment & Acronym \\
\hline 1 & Euro/Dollar Parity & 1 & EUROUSD \\
2 & VIX & 3 & VIX \\
3 & Price of Crude Oil Brent & 3 & COILBR \\
4 & Two-Year US Treasury Bond Interest Rate & 1 & ChATW FED \\
5 & Ten-Year US Treasury Bond Interest Rate & 1 & Thomson Reuters Data Stream \\
6 & FED Policy Interest Rate & 1 & Thomson Reuters Data Stream \\
\hline
\end{tabular}

Note: Treatment shows how the series is transformed before added to the database, with $1=$ level and $3=\log$ difference.

Table 4

Bai-Ng factor determination test and cumulated variance share for monetary policy tools.

\begin{tabular}{llll}
\hline \# Factors & PCP1 & PCP2 & PCP3 \\
\hline 1 & 0.5447 & 0.5342 & 0.5261 \\
2 & 0.4752 & 0.4542 & 0.4381 \\
3 & $0.4653^{*}$ & $0.4338^{*}$ & $0.4097^{*}$ \\
4 & 0.4890 & 0.4470 & 0.4148 \\
5 & 0.5163 & 0.4639 & 0.4236 \\
6 & 0.5494 & 0.4864 & 0.4381 \\
7 & 0.5849 & 0.5114 & 0.4551 \\
8 & 0.6314 & 0.5475 & 0.4831 \\
9 & 0.6794 & 0.5849 & 0.5125 \\
\hline
\end{tabular}

Note: * is the optimal number of factor variables.

Table 5

Bai-Ng factor determination test and cumulated variance share for economic state variables.

\begin{tabular}{|c|c|c|c|c|}
\hline \# Factors & PCP1 & PCP2 & PCP3 & Cumulated Variance Share \\
\hline 1 & 0.7433 & 0.7478 & 0.7354 & 0.999848 \\
\hline 2 & 0.6882 & 0.6972 & 0.6724 & 0.999900 \\
\hline 3 & 0.6501 & 0.6637 & 0.6263 & 0.999939 \\
\hline 4 & 0.6354 & 0.6535 & 0.6038 & 0.999964 \\
\hline 5 & $0.6226^{*}$ & $0.6452^{*}$ & 0.5830 & 0.999980 \\
\hline 6 & 0.6239 & 0.6511 & 0.5764 & 0.999987 \\
\hline 7 & 0.6277 & 0.6595 & $0.5723^{*}$ & 0.999992 \\
\hline 8 & 0.6369 & 0.6732 & 0.5736 & 0.999996 \\
\hline 9 & 0.6519 & 0.6927 & 0.5807 & 0.999998 \\
\hline 10 & 0.6693 & 0.7146 & 0.5902 & 1.0000 \\
\hline
\end{tabular}

Note: * is the optimal number of factor variables.

Table 6

Bai-Ng factor determination test and cumulated variance share for external variables.

\begin{tabular}{|c|c|c|c|c|}
\hline \# Factors & PCP1 & PCP2 & PCP3 & Cumulated Variance Share \\
\hline 1 & 0.6812 & 0.6116 & 0.6092 & 0.4543 \\
\hline 2 & 0.6253 & 0.4859 & 0.4811 & 0.6505 \\
\hline 3 & $0.5964 *$ & 0.3874 & 0.3802 & 0.8193 \\
\hline 4 & 0.6016 & $0.3230^{*}$ & $0.3133^{*}$ & 0.9539 \\
\hline 5 & 0.6984 & 0.3501 & 0.3380 & 0.9963 \\
\hline 6 & 0.8338 & 0.4158 & 0.4013 & 1.0000 \\
\hline
\end{tabular}

Note: * is the optimal number of factor variables.

bands include a horizontal zero line for any period, this can be interpreted as that the impulse response for this particular period is not different from zero.

First, we discuss how the economic state variables respond when a one-standard-deviation shock is given to the BIST Overnight Interest Rate, where the other three interest rates are incorporated into the $F_{t}$ vectors. We look at the effect of this policy rate first because the CBRT considers this tool as the main indicator of its monetary policy stance (see CBRT, 2013; 2016). A positive innovation in the BIST Overnight Interest Rate increases credit interest rates (consumer credit interest rate, commercial TL credit interest rate and 


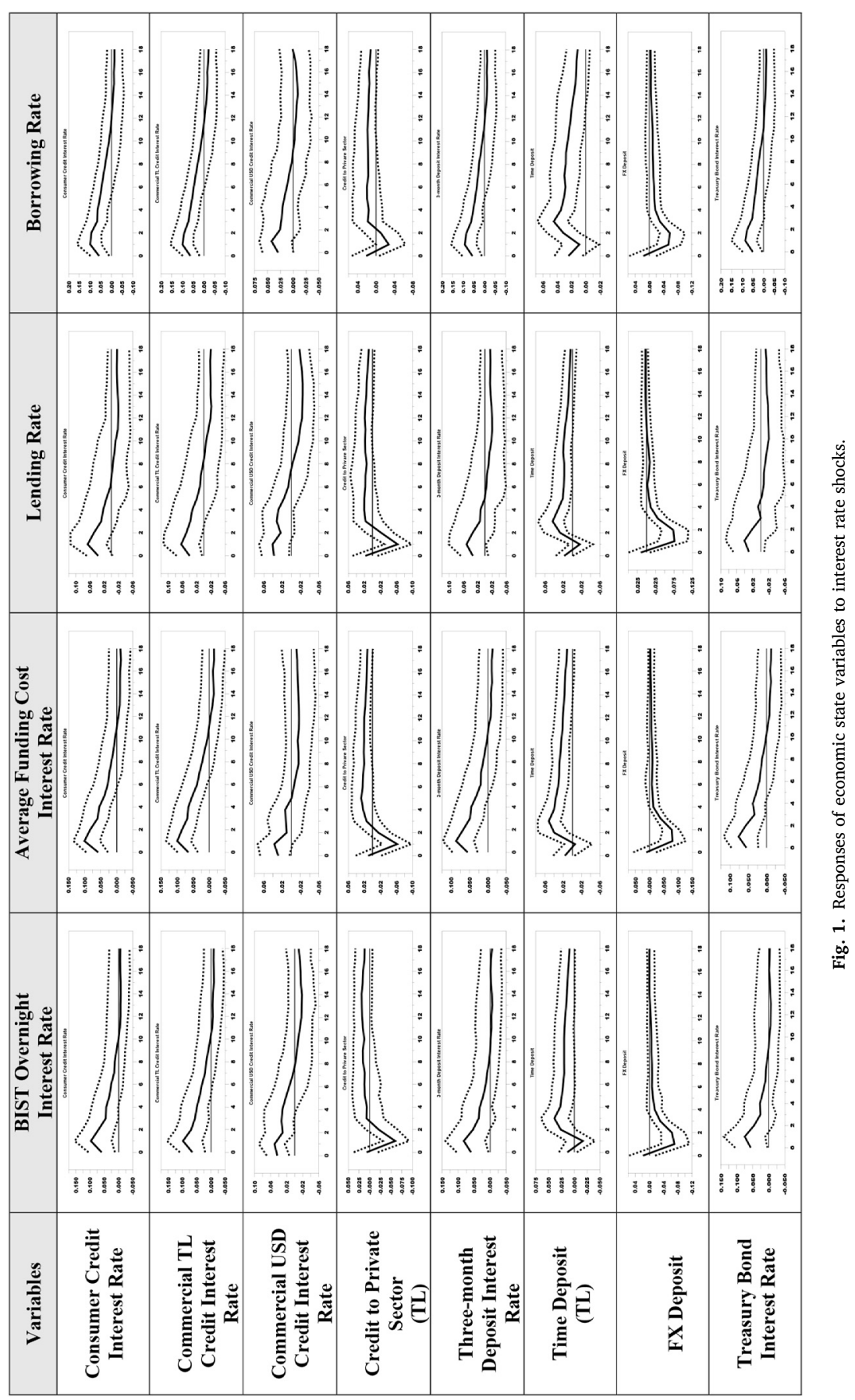




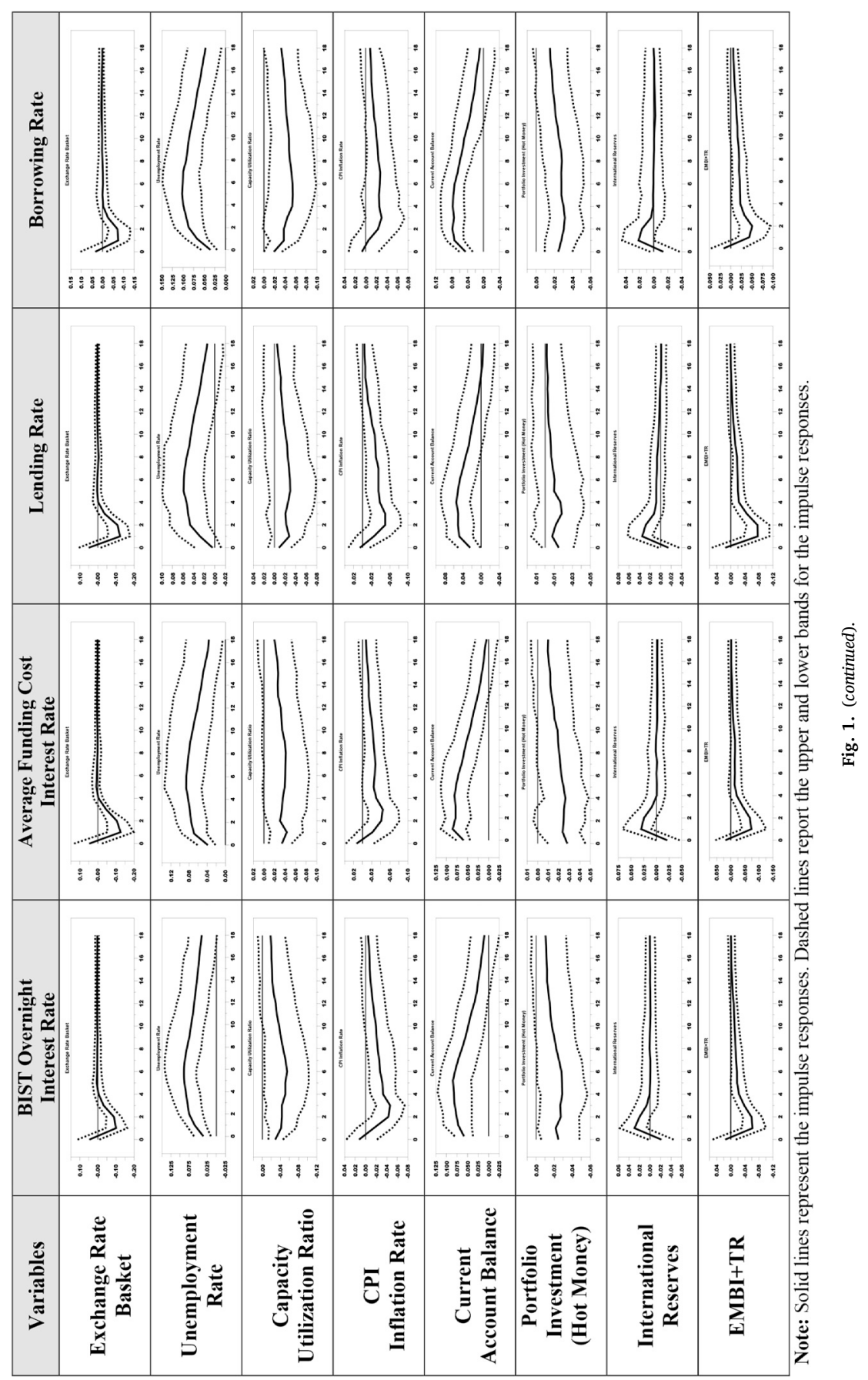


commercial USD credit interest rates), the three-month deposit interest rate and the Treasury bond interest rate (note that credit interest rates increase faster than deposit interest rates do). Credit to the private sector decreases and TL-denominated deposits increase with a delay. Interestingly, FX deposits decrease, which makes sense because agents are likely to benefit from higher returns in TLdenominated deposits by converting their FX deposits to TL. ${ }^{10}$

Further, a positive innovation in the BIST Overnight Interest Rate appreciates domestic currency with a delay, decreases economic performance (increases the unemployment rate and decreases the capacity utilization ratio) and increases the current account balance. This last result may be due to lower imports via lower aggregate demand and firms might increase their exports due to lower domestic demand. Another result of positive innovation in the BIST Overnight Interest Rate is that portfolio investments decrease. Here, a negative portfolio investment (short-term capital flows) is an indication of net capital flows to Turkey, ${ }^{11}$ which is parallel with economic priors. Moreover, the CBRT's international reserves increase after the first month. On the other hand, the EMBI + TR, which is Turkey's sovereign risk premium, decreases after the first month. Overall, we claim that the reported evidence is parallel with economic priors.

In the second column, we report the impulse responses when a one-standard-deviation shock is given to the Average Funding Cost Interest Rate, which is the direct measure of commercial banks' cost for their funding from the central bank. Similar to the previous analysis, we incorporate the other three interest rates into the $F_{t}$ vectors. The CBRT (2015) also emphasizes that the Average Funding Cost is a measure of liquidity, along with the interest rate corridor, and is important for commercial banks' deposits. Note that the oneweek funding cost is lower than the overnight cost but the former has more restrictions to use. Thus, the CBRT can have lower levels of funds provided at one-week-funding facility, which increases commercial banks' average funding and borrowing costs. Ünalmõş (2015) and Kara (2015), both from the CBRT, claim that the Average Funding Cost Interest Rate should be considered with the BIST Overnight Interest Rate in a monetary policy stance, and Kara (2015) further argues that the Borrowing Rate should also be included in those considerations. Küçük, Özlï, Talaslõ, Ünalmõş, and Yüksel (2014) note that borrowing rate is more reflective of the CBRT's liquidity position.

The second column of Fig. 1 reveals that the shapes of the impulse responses for the Average Funding Cost Interest Rate are essentially identical to the ones reported in the first column. However, the interest rate responses on TL-denominated contracts such as consumer credit interest rates, commercial credit interest rates, the three-month deposit interest rate and the Treasury bond interest rate are statistically significant at longer periods with narrower confidence bands. These findings suggest that the Average Funding Cost Interest Rate has a longer and slightly stronger effect on banks' liabilities. This is parallel to what Kara (2015) suggests, which is that the Average Funding Cost Interest Rate has stronger effect on banks' deposits. On the other hand, the Average Funding Cost Interest Rate has a shorter and slightly lower statistically significant effect compared to the BIST Overnight Interest Rate on capacity utilization ratio, CPI inflation rate and portfolio investments. Further, the level of significance and confidence bands are similar to the other variables, which may suggest that the effect of Average Funding Cost on macroeconomic performance variables is weaker on these variables than the variables for the BIST rate.

The third column reports the impulse responses when a one-standard-deviation shock is given to the Lending Rate (marginal funding rate), which is the overnight funding rate quoted at the upper bound of the corridor (CBRT, 2014). Kara (2015) notes that this rate is important for commercial banks' lending rates to the private sector. The responses of the credit and deposit interest rates to the Lending Rate are similar to the effects of shocks on the BIST Overnight Interest Rate and Average Funding Cost Interest Rate, but with slightly wider confidence bands (i.e. at a lower level of statistical significance). Further and importantly, the volume effects on interest rates and credits as well as on deposit volumes are similar. On the other hand, we could not find a shock to the Lending Rate, and this effect is more important than the BIST Overnight Interest Rate and Average Funding Cost Interest Rate's effects on economic state variables such as unemployment rate, CPI inflation rate, current account balance, international reserves, EMBI + TR and exchange rate. The responses of the capacity utilization ratio and portfolio investments to the Lending Rate are not statistically significant for the 18 periods that we consider. However, the most pronounced effect of all four interest rates is observed on international reserves, which increase between the first and second periods in a statistically significant fashion.

The last column is for shocks to the Borrowing Rate. Kara (2015) notes that this rate is important for banks' deposit interest rates along with Average Funding Cost Interest Rate and short-term capital flows. When we look at how the deposit interest rate and deposit volume responds, our evidence supports Kara's argument. The three-month deposit interest rate increases for 13 periods and the time deposits increase for 18 periods. These increases are statistically significant for the first five periods in the former and between the second and twelfth periods for the latter. Compared to the Lending Rate, these effects are more pronounced. On the other hand, a onestandard-deviation shock to the Borrowing Rate seems to affect the credit interest rate (possibly due to the higher cost of the Borrowing Rate for commercial banks), but we could not find a statistically significant effect for the credit volume (this finding also supports the CBRT's propositions). It also seems that a positive shock to the Borrowing Rate affects the unemployment rate and capacity utilization ratio for longer periods in a statistically significant fashion compared to a shock to the Lending Rate. Importantly, a positive shock to the Borrowing Rate affects portfolio investments, which is also what the CBRT (2012) argues. Last, the Borrowing Rate has the longest statistically significant effect on portfolio investments among all four interest rates, and these results are parallel with Aysan et al.

\footnotetext{
10 We did not look at foreign-currency-denominated credits extended by the banking sector because this variable may not be sensitive to interest rates; first, such credits are extended to companies that have foreign currency revenues; second, leasing companies may offer better rates due to the tax advantages of leasing contracts for machines and equipment.

11 We measured short-term capital flows using Loungani and Mauro's (2000) method from the Balance of Payments and International Investment Position Manual, 6th Edition; BPM6. The Broad Hot Money definition consists of the sum of Net Errors and Omissions, Other Investment (Assets) and Other Investment (Liabilities) held by entities other than monetary authorities, the government and banks, plus Other Investment (Assets) and Other Investment (Liabilities) held by banks, plus Net Flows of Portfolio Investment Assets and Liabilities in the form of Debt Securities.
} 


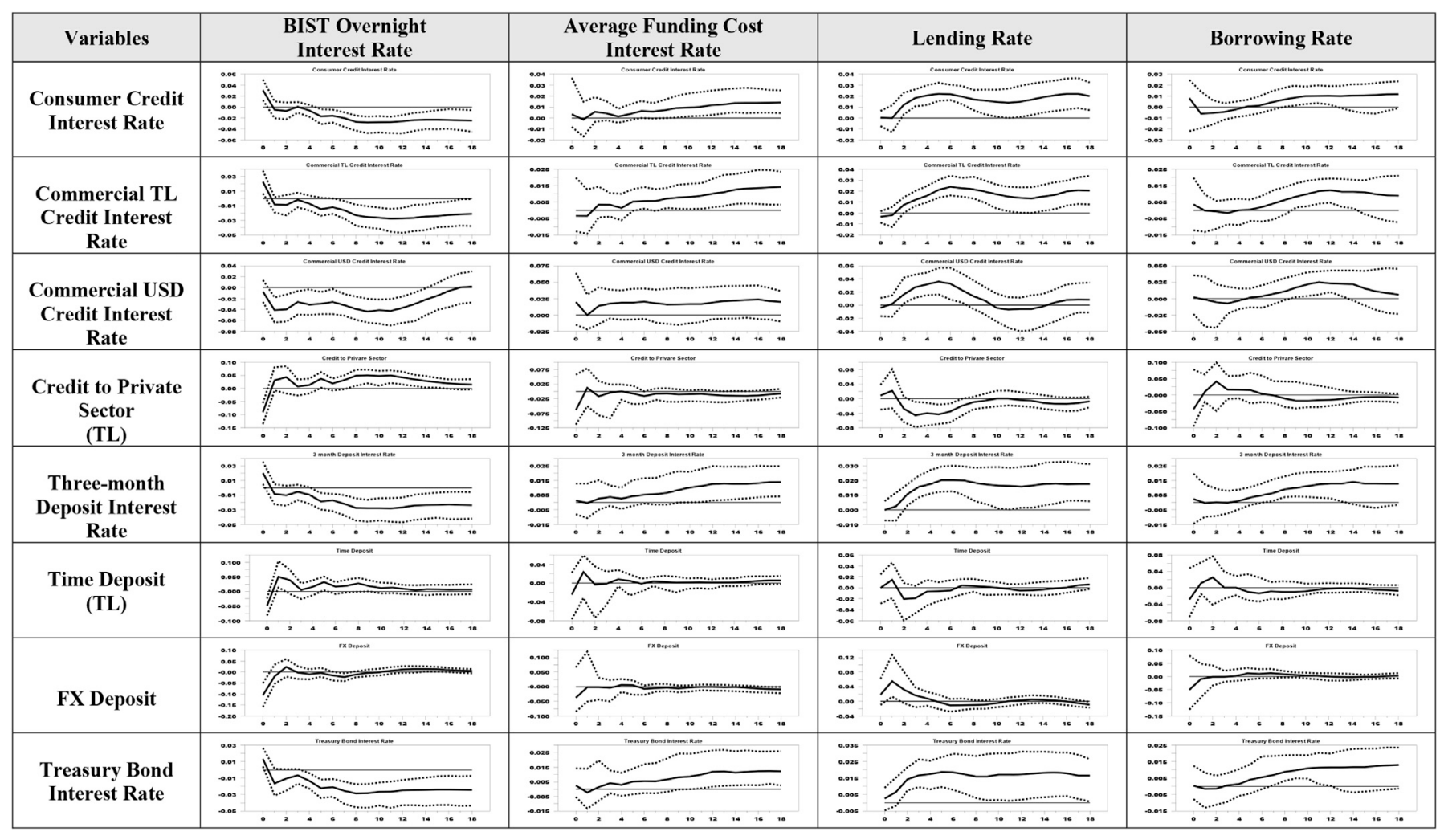

Fig. 2. Responses of economic state variables to interest rate shocks with the Bernanke et al. (2005) method. 


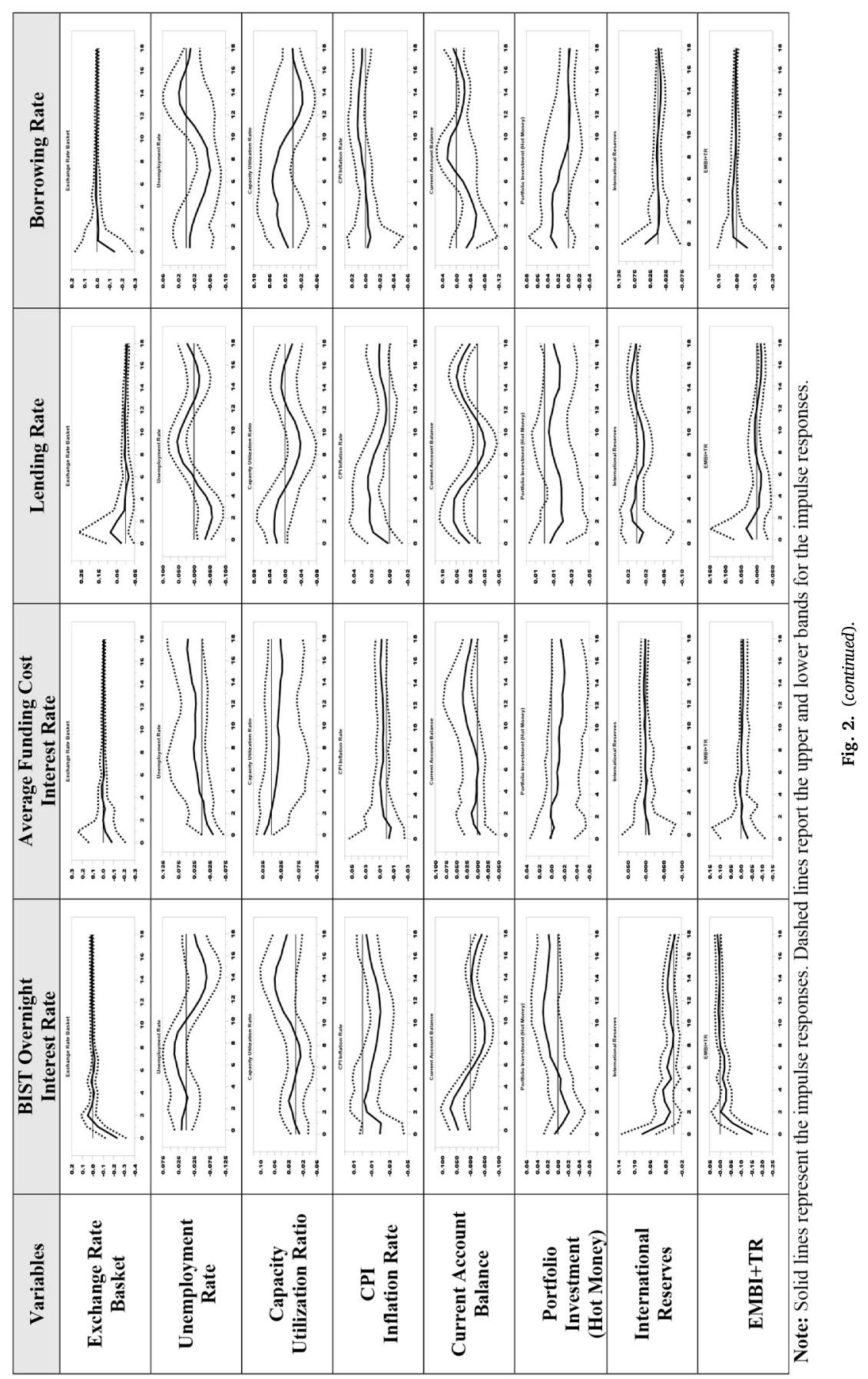


(2014), Küçük et al. (2014) and Kara (2015).

Next, we gathered a set of empirical evidence on alternative specifications, which validate the results we report in Fig. 1. In the first alternative, we assumed the CBRT has one policy tool and we treated all other policy tools as if they were the economic state variables. In other words, we replicated Bernanke et al.'s (2005) FAVAR model but considered the remaining 83 variables as economic state variables, including 24 other policy tools that we assume the central bank controls. Fig. 2 reports the corresponding impulse responses when a one-standard-deviation shock is given to one of the four policy variables that we consider at a given time. We found that the confidence bands are wider and we also found a set of irregularities; for example, an increase in the Lending Rate increases the CPI inflation rate (price puzzle) and decreases the unemployment rate. A positive shock to the BIST Overnight Interest Rate decreases the three-month deposit interest rate, the consumer credit interest rate and the Treasury bond interest rate after the fourth period in a statistically significant fashion. Thus, we claim that the estimates shown in Fig. 1 are more aligned with economic priors and are statistically stronger than the estimates gathered when we assume that there is only one policy variable.

Our benchmark specification in Fig. 1 allows that the CBRT controls 25 policy variables simultaneously. In the second alternative, we included the remaining 24 policy tools as exogenous variables to the system and did not include $G_{t}$ and $\widehat{G}_{t}$ in the left-hand sides of Equations (1)-(4). Thus, we did not allow any feed-in mechanism that works through these 24 policy tools, but rather we entered three factors gathered from the policy tools as exogenous variables to the system as control variables. Fig. 3 reports the relevant impulse responses, and as shown, a set of irregularities again appears in the economic state variables. For example, a positive innovation in the BIST Overnight Interest Rate, Average Funding Cost Interest Rate and Lending Rate decrease the unemployment rate and increases the capacity utilization ratio. These effects are statistically significant for the BIST Overnight Interest Rate and the Average Funding Cost Interest Rate. Moreover, the price puzzle is present; a positive innovation in those interest rates increases prices for two to ten periods. These effects are statistically significant for the BIST Overnight Interest Rate for the first two periods. Thus, accounting for those 24 other policy tools is important and allows better capture of monetary policy's effect on Turkey's economy.

Fig. 4 repeats the same exercise, assuming the CBRT has one policy tool, but excluded the other 24 policy variables from the analyses. To be particular, we assumed the CBRT has one policy tool and we excluded all the policy variables from the analyses. In other words, we replicated Bernanke et al.'s (2005) FAVAR model but considered only 59 economic state variables as state variables in Fig. 4 whereas Fig. 2 had 83 state variables including policy 59 economic state variables as well as 24 policy variables. Fig. 4 reveals that the supporting evidence involving statistically significant responses is weaker, and a set of irregularities is also present. The domestic currency depreciates with a positive innovation in the Average Funding Cost Interest Rate as well as in the Lending Rate (exchange rate puzzle). The unemployment rate decreases with a positive innovation in the Lending Rate and the capacity utilization ratio increases with a positive innovation in the Average Funding Cost Interest Rate as well as in the Lending Rate.

As a next set of analyses, Table 7 reports the FEVDs of our benchmark model, the impulse responses of which are reported in Fig. 1. For each of the four policy interest rates, we report two statistics. The first is the contribution of the considered policy rate regarding how much variability for that rate and for the 16 economic state variables that we consider in the paper over an 18-period horizon is explained by the policy rate that we consider at a given time. The second statistic is for the $\mathrm{R}^{2}$ for the 17 variables regarding how much the eight common factors and the policy rate explain each variable.

As Bernanke et al. (2005) note, the monetary policy shocks in the VAR literature explain a relatively small part of the forecast errors for real activity and inflation. A similar result prevails for Turkey (see, for example, Berument, 2007; Berument, Togay and Sahin, 2011). As each of the policy rates we consider is one of the 25 policy tools that the CBRT considers, the explanatory power of a single policy rate must be even smaller. Table 7 suggests that monetary policy rates as a policy tool explain less than $2.5 \%$ of the variability of the economic state variables. Surprisingly, policy rate shocks have relatively more explanatory power for real variables such as unemployment rate and capacity utilization rate. However, a similar conclusion is also drawn for the Euro area by Soares (2013).

When we look at the $\mathrm{R}^{2}$, Table 7 suggests that three (for the policy variables) plus five (for the economic state variables) factors as well as the policy rate $\left(R_{t}\right)$ explain a sizable fraction of each of the policy rate, exchange rate, unemployment rate and capacity utilization rate. However, the factors we gather have less explanatory power for time deposits, FX deposits, CPI inflation rate, portfolio investments and international reserves. Aktaş, Güner, Gürsel, and Uysal (2012) maintain that changes in time deposits and FX deposits are basic financial saving tools for Turkish citizens and that these deposits are likely to be affected by various other factors such as female labor force participation and education rather than by monetary policy stance. Portfolio investments are more likely to be affected by political and geopolitical factors (see Erataş \& Öztekin, 2010), and CPI inflation rate is more likely to be affected by non-policy tools such as fresh fruit and vegetable prices (food and non-alcoholic beverages), excise taxes on alcoholic beverages and cigarette (which have a $29 \%$ weight in consumer baskets for 2016 (see Turkish Statistical Institute, 2017)).

\subsection{Caveat}

The CBRT actively used different interest rates to affect Turkey's economic performance in different periods. For example, the Borrowing Rate was actively used after 2001 until 2010 due to the excess liquidity created after the 2001 financial crisis. Thus, the Borrowing Rate was the main policy tool for this period. Similarly, the CBRT has been employing the One-Week Repo Interest Rate as a since May 2010. The purpose of this paper is to assess the different effects of different policy tools on economic performance. Historical decomposition analyses could be used to determine which interest rate was the main factor for the different economic performance variables at different periods, however, as this method is not well-established within the FAVAR framework, we left this analysis for a future study.

The CBRT is not the sole authority that designs monetary policy; other institutions such as the Banking Regulatory and Supervisory Agency (BRSA) and the Financial Stability Committee (FSC) also contribute to it. The BRSA sets capital adequacy ratios, differentiated risk 


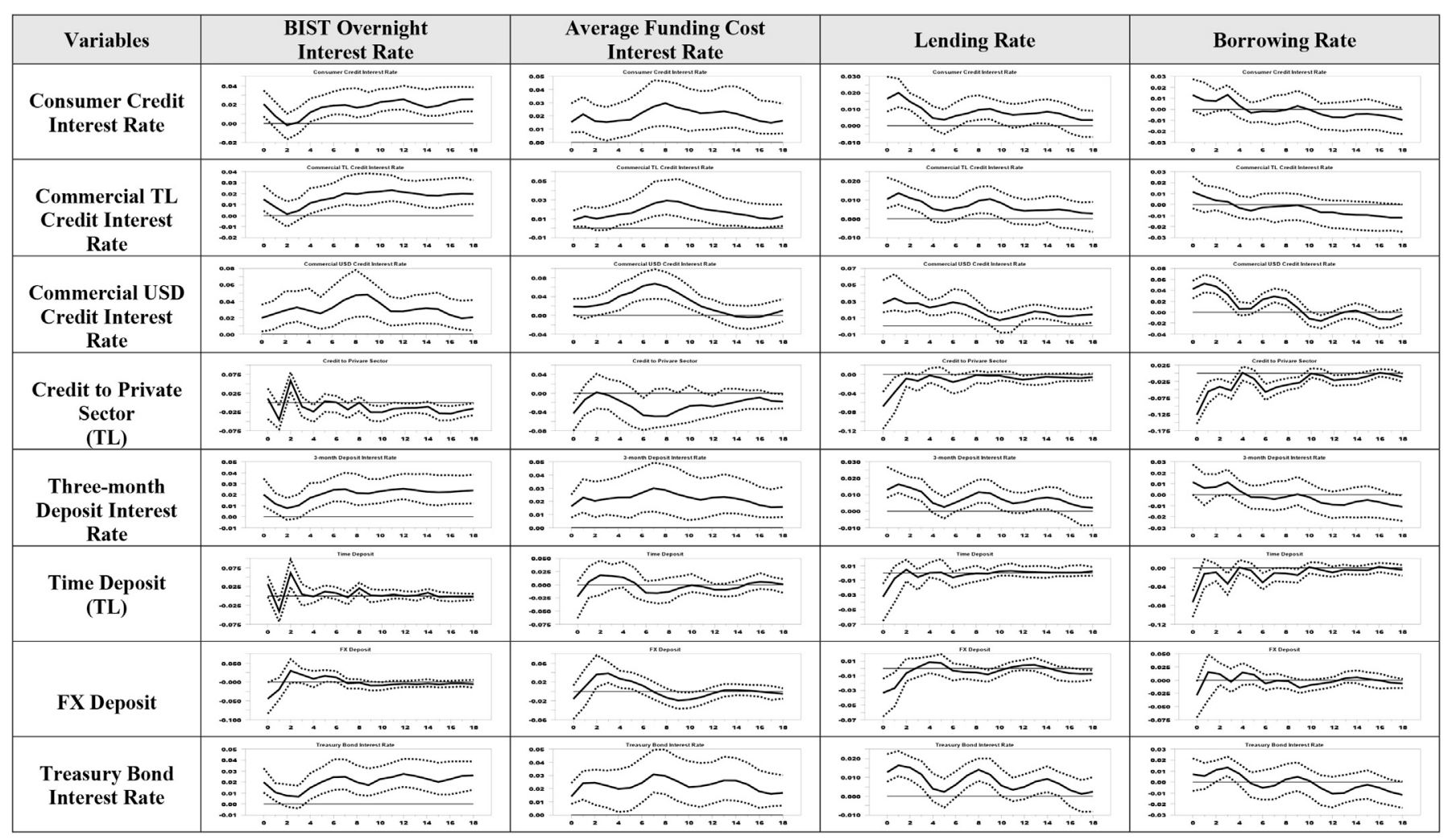

Fig. 3. Responses of economic state variables to interest rate shocks that other policy tools did not respond to. 


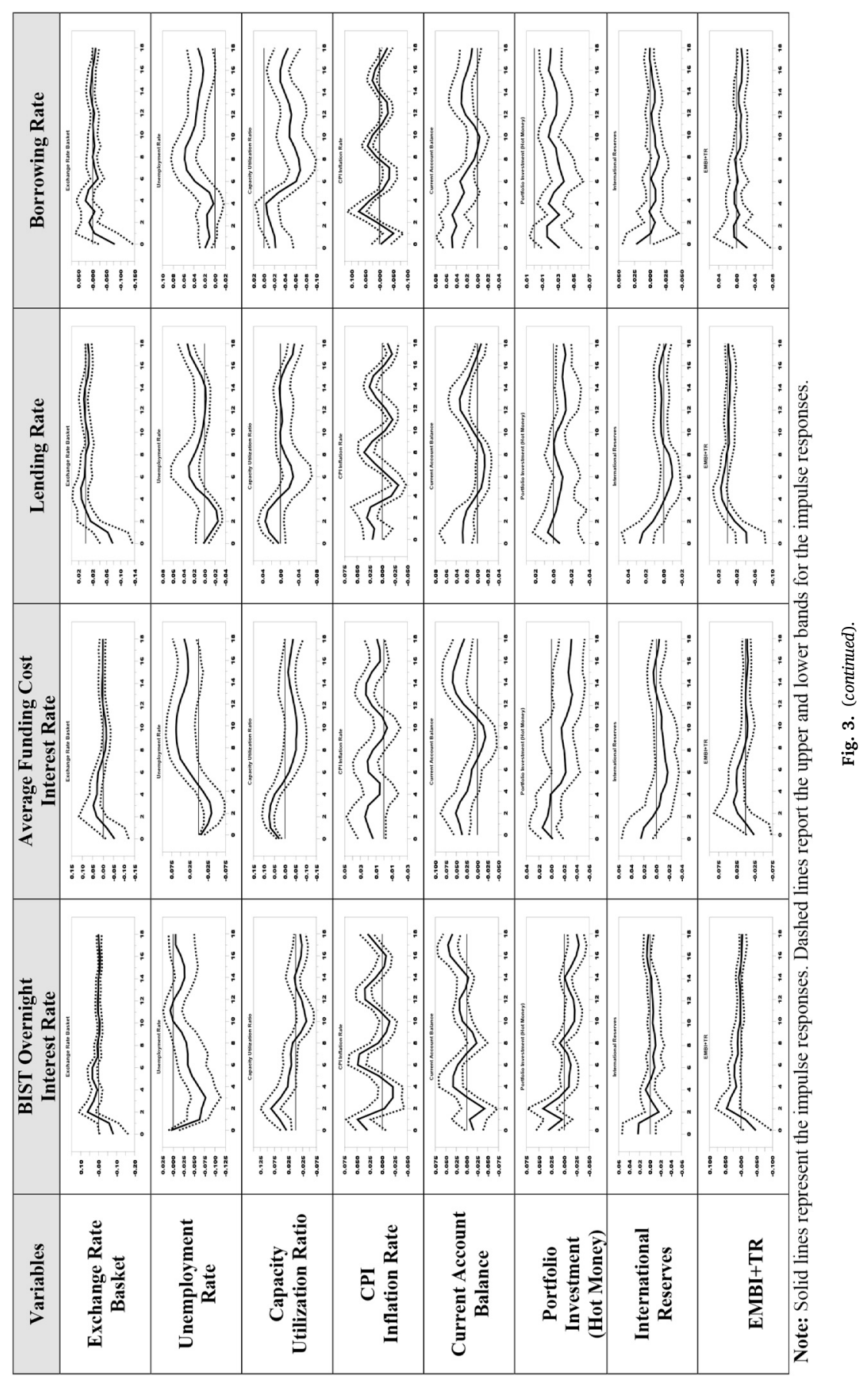




\begin{tabular}{|c|c|c|c|c|}
\hline Variables & $\begin{array}{l}\text { ernight } \\
\text { Rate }\end{array}$ & $\begin{array}{l}\text { Average Funding Cost } \\
\text { Interest Rate }\end{array}$ & Lending Rate & Borrowing Rate \\
\hline $\begin{array}{l}\text { Consumer Credit } \\
\text { Interest Rate }\end{array}$ & $\frac{1}{2 \ldots \ldots \ldots *}$ & ${ }^{\infty}$ & $\frac{4}{0.0 .}$ & $\underbrace{6}_{0 .}$ \\
\hline $\begin{array}{l}\text { Commercial TL } \\
\text { Credit Interest } \\
\text { Rate }\end{array}$ & ב & ( & 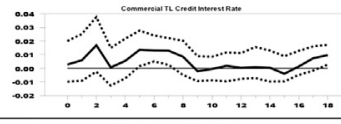 & 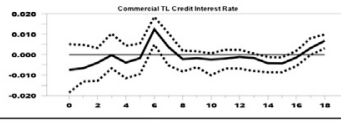 \\
\hline $\begin{array}{c}\text { Commercial USD } \\
\text { Credit Interest } \\
\text { Rate } \\
\end{array}$ & $\frac{10}{2012}$ & ( & ${ }_{0}^{-}$ & . \\
\hline $\begin{array}{l}\text { Credit to Private } \\
\text { Sector } \\
\text { (TL) }\end{array}$ & . & רוn & ב. & $=$ \\
\hline $\begin{array}{c}\text { Three-month } \\
\text { Deposit Interest } \\
\text { Rate }\end{array}$ & רי & בר & 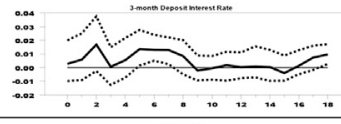 & $\underbrace{}_{0.12}$ \\
\hline $\begin{array}{l}\text { Time Deposit } \\
\text { (TL) }\end{array}$ & . & 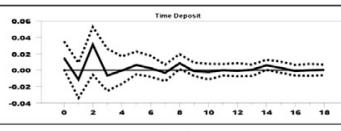 & $\underset{n=1}{\cdots}$ & 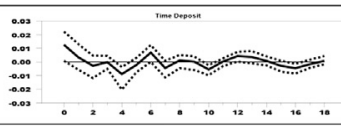 \\
\hline FX Deposit & . & 业 & $\begin{array}{lll} & \\
\ldots\end{array}$ & 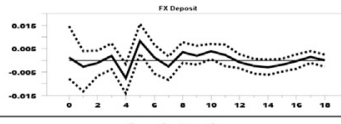 \\
\hline $\begin{array}{l}\text { Treasury Bond } \\
\text { Interest Rate }\end{array}$ & . & $\mathrm{S}^{\infty}$ & (a) & A \\
\hline
\end{tabular}

Fig. 4. Responses of economic state variables to interest rate shocks when there is only one policy tool. 


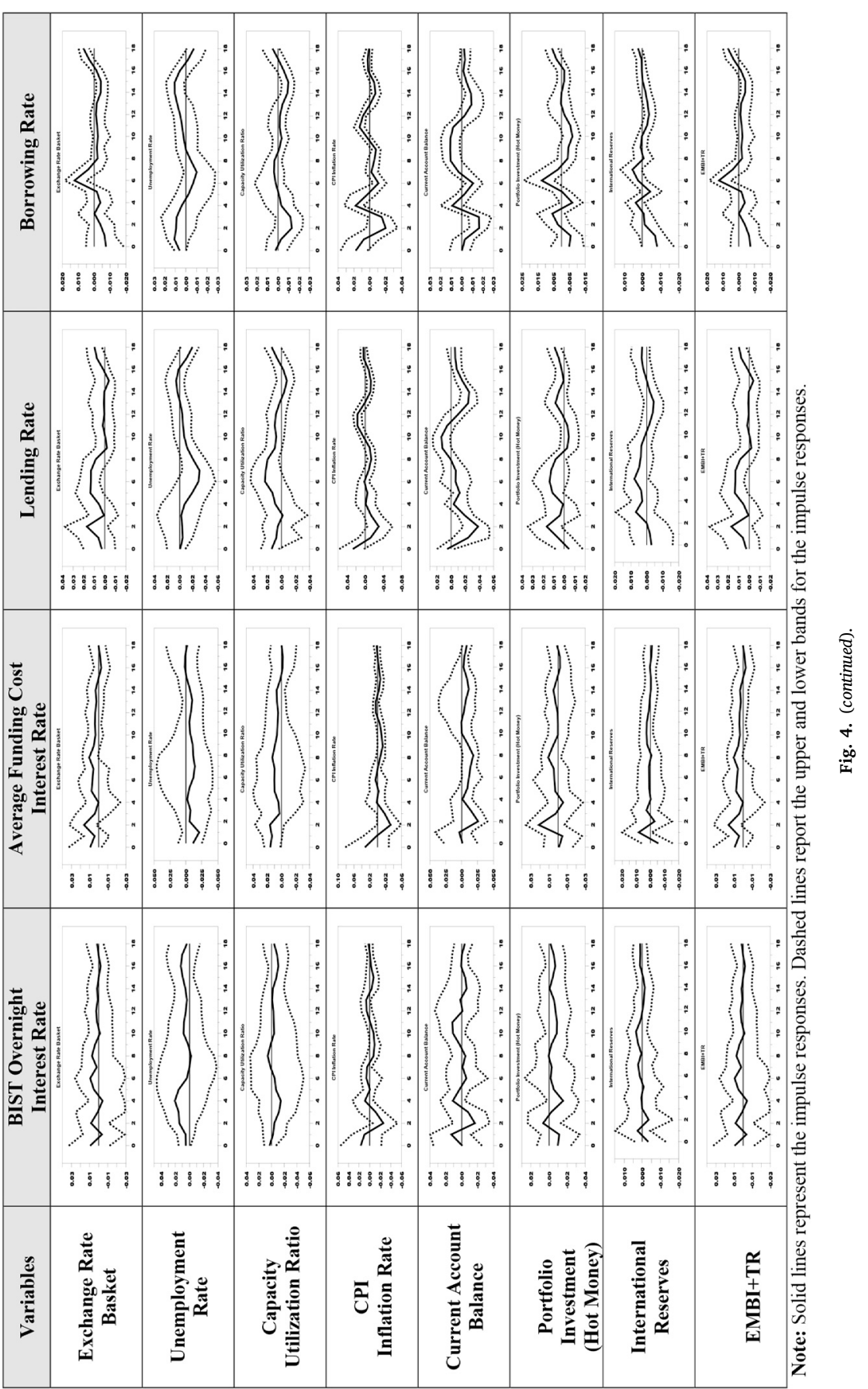


Contribution of policy shocks to variance of the common components.

\begin{tabular}{|c|c|c|c|c|c|c|c|c|}
\hline & \multicolumn{2}{|c|}{ BIST Overnight Interest Rate } & \multicolumn{2}{|l|}{$\begin{array}{l}\text { Weighted Average Interest } \\
\text { Rate }\end{array}$} & \multicolumn{2}{|l|}{ Lending Interest Rate } & \multicolumn{2}{|l|}{ Borrowing Interest Rate } \\
\hline & Variance Decomposition & $\mathrm{R}^{2}$ & Variance Decomposition & $\mathrm{R}^{2}$ & Variance Decomposition & $\mathrm{R}^{2}$ & Variance Decomposition & $\mathrm{R}^{2}$ \\
\hline Policy Rate & 1.26 & & 0.89 & & 0.83 & & 1.21 & \\
\hline Consumer Credit Interest Rate & 1.06 & 71.29 & 0.78 & 70.3 & 1.88 & 64.57 & 0.67 & 70.04 \\
\hline Commercial TL Credit Int. Rate & 1.14 & 67.4 & 0.85 & 63.34 & 2.34 & 60.96 & 0.78 & 65.25 \\
\hline Commercial USD Credit Int. Rate & 1.65 & 51.95 & 2.24 & 51.56 & 1.1 & 52.65 & 1.45 & 51.27 \\
\hline Credit to Private Sector & 1.45 & 50.89 & 0.7 & 51.62 & 0.81 & 49.43 & 1.31 & 49.74 \\
\hline Three-month Deposit Interest Rate & 1.21 & 71.43 & 0.85 & 70.06 & 2.19 & 60.45 & 0.54 & 69.93 \\
\hline Time Deposit & 1.81 & 32.41 & 0.82 & 30.92 & 0.94 & 29.23 & 1.04 & 32.62 \\
\hline FX Deposit & 1.5 & 39.78 & 0.96 & 40.8 & 0.78 & 35.51 & 1.03 & 41.16 \\
\hline Interest Rate of Treasury Bond & 1.15 & 71.27 & 0.86 & 71.48 & 2.06 & 59.97 & 0.58 & 68.76 \\
\hline Exchange Rate Basket & 1.26 & 88.24 & 0.89 & 88.43 & 0.83 & 91.98 & 1.21 & 90.34 \\
\hline Unemployment Rate & 2.03 & 94.24 & 0.46 & 93.13 & 0.97 & 94.68 & 0.82 & 97.06 \\
\hline Capacity Utilization Ratio & 2.34 & 84.71 & 0.78 & 87.62 & 1.72 & 90.31 & 0.91 & 89.34 \\
\hline CPI Inflation Rate & 1.67 & 35.03 & 1.11 & 41.29 & 1.2 & 31.07 & 0.83 & 33.71 \\
\hline Current Account Balance & 2.11 & 52.31 & 0.81 & 42.03 & 1.1 & 44.4 & 1.03 & 47.02 \\
\hline Portfolio Investment (Hot Money) & 1.83 & 26.27 & 0.83 & 26.8 & 1.1 & 24.05 & 0.92 & 29.69 \\
\hline International Reserves & 1.49 & 28.75 & 0.95 & 28.61 & 0.97 & 29.24 & 1.07 & 30.74 \\
\hline $\mathrm{EMBI}+\mathrm{TR}$ & 1.6 & 46.00 & 0.95 & 44.32 & 0.77 & 45.51 & 0.99 & 45.47 \\
\hline
\end{tabular}

Notes: Variance Decomposition reports the fraction of the variance of the forecast error of economic variable factors at the 18-month horizon, explained by each policy rate. $\mathrm{R}^{2}$ refers to the fraction of the variance of the variable explained by common factors for economic state and policy variable factors as well as the policy rate that is considered for that column.

weights and general provisions for consumer loans, higher minimum payments for credit card debt, and loan-to-value caps (e.g. for housing loans) for banks. The FSC consists of various major governmental institutions such as the CBRT, BRSA, Treasury, Capital Markets Board, and Saving Deposit Insurance Fund. The FSC met about 30 times for the sample that we consider and took various actions within the mandates of those institutions (see Kara, 2016 for details). Our analyses overlook these differences because these variables do not have enough variability to incorporate in the FAVAR analyses, and most regulations are not easy to quantify with the publicly available data.

\section{Conclusion}

Conventional FAVAR models allow policy makers to set up a single policy tool that monetary policy authorities control, and in which a large number of economic state variables are captured by a few factors. However, central banks may have more than one policy tool through which to conduct their monetary policies, and may use these policy tools simultaneously, though not independently. By using an extension of the FAVAR model, this paper assesses how the various policy interest rates that central banks control affect, for example, commercial banks' balance sheets and economic performance variables differently. Our extension allows (i) central banks to use multiple tools and (ii) that each tool can have a different effect on economic state variables. To introduce this extension, we use factor analyses of the economic state variables, as in Bernanke et al. (2005), and factor analysis of the monetary policy tools.

The empirical evidence gathered from Turkey for the period between December 2001 and April 2016 suggests that BIST Overnight Interest Rate changes affect economic performance parallel to economic priors. Moreover, a positive shock to the Average Funding Cost Interest Rate has a longer and slightly stronger effect on bank deposits but a slightly weaker effect on the capacity utilization ratio and the CPI inflation rate and portfolio investments compared to the BIST Overnight Interest Rate. Similarly, the Borrowing Rate and Lending Rate have weaker effects on economic state variables such as CPI inflation rate and capacity utilization ratio compared to the BIST Overnight Interest Rate, but a stronger effect on bank balance sheets. Portfolio investments are the most affected by the Borrowing Rate. Thus, this paper provides empirical evidence that the four interest rates we consider have different effects on economic state variables, and therefore, selecting different policy tools provides an environment for economic policy makers to differentiate the effects of their tools for differentiated desired outcomes.

\section{References}

Agénor, P. R., \& Da Silva, L. A. P. (2013). Inflation targeting and financial stability: A perspective from the developing world. Inter-American Development Bank.

Aktaş, A., Güner, D., Gürsel, S., \& Uysal, G. (2012). Structural determinants of household saving in Turkey: 2003-2008. BETAM Working Paper, No.007, May.

Aysan, A. F., Fendoglu, S., \& Kilinc, M. (2014). Managing short-term capital flows in new central Banking: Unconventional monetary policy framework in Turkey. Eurasian Economic Review, 4(1), 45-69.

Bai, J., \& Ng, S. (2002). Determining the number of factors in approximate factor models. Econometrica, 70(1), 191-221.

Başçõ, E. (Ed.). (2013). Governor Başçõ's presentation at the BIS-Bank of Russia conference. Moscow, July 19, 2013.

Bașçõ, E., \& Kara, A. H. (2011). Financial stability and monetary policy. İktisat İşletme ve Finans, 26(302), 9-25.

Baumeister, C., Liu, P., \& Mumtaz, H. (2010). Changes in the transmission of monetary policy: Evidence from a time-varying factor-augmented VAR. Bank of England Working Paper, 401, 1-48.

Bernanke, B. S., \& Blinder, A. (1992). The federal funds rate and the channels of monetary transmission. American Economic Review, 82(4), 901-921.

Bernanke, B. S., Boivin, J., \& Eliasz, P. (2005). Measuring the effects of monetary policy: A factor-augmented vector autoregressive (FAVAR) approach. The Quarterly Journal of Economics, 120, 387-422.

Berument, M. H. (2007). Measuring monetary policy for small open economy: Turkey. Journal of Macroeconomics, 29(2), 411-430. 
Berument, M. H., Togay, S., \& Sahin, A. (2011). Identifying the liquidity effects of monetary policy shocks for a small open economy: Turkey. Open Economies Review, 22(4), 649-667.

Binici, M., Erol, H., Kara, A. H., Özlü, P., \& Ünalmõş, D. (2013). Faiz Koridoru Bir Makro İhtiyati araç Olabilir mi? CBRT Economic Note, (13/19).

Blaes, B. (2009). Money and monetary policy transmission in the Euro Area: Evidence from FAVAR-and VAR approaches. Deutsche Bundesbank Discussion Paper Series 1: Economic Studies, (18/2009), 1-35.

Boivin, J., Kiley, M. T., \& Mishkin, F. S. (2010). How has the monetary transmission mechanism evolved over time? NBER Working Paper Series, 15879, 1-88.

Borio, C. (2011). Central banking post-crisis: What compass for uncharted waters? BIS Working Papers, 353, 1-17.

Central Bank of the Republic of Turkey. (2009). Monetary and exchange rate policy for 2010.

Central Bank of the Republic of Turkey. (2010a). Monetary and exchange rate policy for 2011.

Central Bank of the Republic of Turkey. (2010b). Monetary policy Exit Strategy, 14 April 2010.

Central Bank of the Republic of Turkey. (2012). Monetary and exchange rate policy for 2013.

Central Bank of the Republic of Turkey. (2013). Monetary and exchange rate policy for 2014.

Central Bank of the Republic of Turkey. (2014). Monetary and exchange rate policy for 2015.

Central Bank of the Republic of Turkey. (2015). Normalization of global monetary policies, framework of interest rate corridor and Turkish Lira liquidity management and simplification steps. Bulletin, December(37).

Central Bank of the Republic of Turkey. (2016). Inflation report-IV (Ankara, Turkey).

Cerutti, E., Claessens, S., \& Laeven, L. (2015). The use and effectiveness of macroprudential Policies: New evidence. IMF Working Papers, WP/15/61.

Cerutti, E., Correa, R., Fiorentino, E., \& Segalla, E. (2016). Changes in prudential policy instruments-a new cross-country database. IMF Working Papers, WP/16/110.

Ceylan, B. C., Dogan, B., \& Berument, H. (2014). An interest-rate-spread based measure of Turkish monetary policy. Applied Economics, 46(15), 1804-1813.

Chen, H., Cúrdia, V., \& Ferrero, A. (2012). The macroeconomic effects of large-scale asset purchase programmes. The Economic Journal, 122(564), F289-F315.

Dogan, B., Sahin, A., \& Berument, M. H. (2016). Rethinking interest rate volatility as a macroprudential policy tool. Middle East Development Journal, 8(1), 109-126. Ekinci, M. F., Erdem, F. P., \& Kilinc, Z. (2015). Credit growth, current account and financial depth. Applied Economics, 47(17), 1809-1821.

Erataş, F., \& Öztekin, D. (2010). Determinants of short term capital flows: Turkish example (in Turkish) Ekonomi Bilimleri Dergisi, 2(2).

Fernald, J. G., Spiegel, M. M., \& Swanson, E. T. (2014). Monetary policy effectiveness in China: Evidence from a FAVAR model. Journal of International Money and Finance, 49, 83-103.

Ganioğlu, A. (2012). Finansal Krizlerin Belirleyicileri Olarak Hõzlõ Kredi Genişlemeleri ve Cari İşlemeler Açõgõ. CBRT Working Paper, 12(31), 1-28.

Ghilardi, M. F., \& Peiris, S. J. (2016). Capital flows, financial intermediation and macroprudential policies. Open Economies Review, 27(4), 721-746.

Gupta, R., Jurgilas, M., \& Kabundi, A. (2010). The effect of monetary policy on real house price growth in South Africa: A factor-augmented vector autoregression (FAVAR) approach. Economic Modelling, 27(1), 315-323.

He, Q., Leung, P. H., \& Chong, T. T. L. (2013). Factor-augmented VAR analysis of the monetary policy in China. China Economic Review, 25, 88-104.

Igan, D., Kabundi, A., Nadal de Simone, F., \& Tamirisa, N. (2013). Monetary policy and balance sheet. IMF Working Papers, 13(158), 1-36.

Im, K. S., Pesaran, M. H., \& Shin, Y. (2003). Testing for unit roots in heterogeneous panels. Journal of Economics, 115, 53-74.

Kara, A. H. (2012). Monetary policy in the post-crises period. Iktisat İsletme ve Finans, 27(315), 9-36.

Kara, A. H. (2015). Interest rate corridor and monetary policy stance (in Turkish) CBRT Research Notes in Economics, 2015-13, 1-12.

Kara, A. H. (2016). Turkey's experience with macroprudential policy. BIS Papers No, 86.

Kozicki, S. (2001). Why do central banks Monitor so Many inflation indicators? Federal Reserve Bank of Kansas City Economic Review, 86, 5-42.

Küçük, H., Özlü, P., Talaslõ, A., Ünalmõş, D., \& Yüksel, C. (2014). Interest rate corridor, liquidty management and the overnight spread (in Turkish). CBRT Working Paper, 14-02, 1-37.

Loungani, P., \& Mauro, P. (2000). Capital flight from Russia. IMF Policy Discussion Paper, (00/6), 1-27.

Medina, J. P., \& Roldós, J. (2014). Monetary and macroprudential policies to manage capital flows. IMF Working Papers, WP/14/30.

Mumtaz, H., \& Zanetti, F. (2013). The impact of the volatility of monetary policy shocks. Journal of Money, Credit and Banking, 45(4), 535-558.

Oduncu, A., Ermisoglu, E., \& Polat, T. (2013a). The effect of CBRT's new policy Mix on the volatility of credit growth. CBRT Research Notes in Economics, (13/27), 1-11. Özatay, F. (2011). The new monetary policy of the central bank: Two targets-three intermediate targets-three tools. İktisat İsletme ve Finans, 26(302), 27-43.

Sahay, R., Arora, V., Arvanitis, T., Faruqee, H., N'Diaye, P., \& Griffoli, T. M. (2014). Emerging market Volatility: Lessons from the taper tantrum. IMF Staff Discussion Note, (14/9), 1-29.

Sahin, A., Dogan, B., \& Berument, M. H. (2015). Effectiveness of the reserve option mechanism as a macroeconomic prudential Tool: Evidence from Turkey. Applied Economics, 47(56), 6075-6087.

Sims, C. (1992). Interpreting the macroeconomic time series Facts: The effects of monetary policy. European Economic Review, 36(5), 975-1000.

Soares, R. (2013). Assessing monetary policy in the Euro area: A factor-augmented VAR approach. Applied Economics, 45(19), 2724-2744.

Stock, J. H., \& Watson, M. W. (1998). Diffusion indexes. NBER Working Paper, 6702.

Stock, J. H., \& Watson, M. W. (2005). Implications of dynamic factor models for VAR analysis. NBER Working Paper Series, 11467, 1-65.

Strongin, S. (1995). The identification of monetary policy disturbances explaining the liquidity puzzle. Journal of Monetary Economics, 35, $463-497$.

Turkish Statistical Institute. (2017). Calculations of consumer price index (in Turkish) 2017. No. 03.

Turner, P. (2016). Macroprudential policies, the long-term interest rate and the exchange rate. BIS Working Papers, 588.

Ünalmõş, D. (2015). Interest rate corridor, liquidity Manegement and effective funding rate in money market (in Turkish). CBRT Research Notes in Economics, 2015-20, $1-13$.

Vargas-Silva, C. (2008). The effect of monetary policy on housing: A factor augmented vector autoregression (FAVAR) approach. Applied Economics Letters, 15, 749-775. 